\title{
O QUE PODE ESTA LÍNGUA? CONSIDERAÇÕES SOBRE O ENSINO DE PORTUGUÊS EM CURSOS SUPERIORES DO IFSP
}

\author{
WHAT CAN THIS LANGUAGE DO? CONSIDERATIONS ON \\ TEACHING PORTUGUESE IN HIGHER EDUCATION COURSES \\ AT IFSP
}

\begin{abstract}
Valmir Luis Saldanha da Silva*
Resumo: O presente artigo tem a função de apresentar os resultados de uma pesquisa sobre o ensino de língua portuguesa em cursos superiores do IFSP (Instituto Federal de São Paulo) campus Campos do Jordão cujos focos não são os dos estudos da linguagem. Através da análise qualitativa das respostas dadas pelos estudantes a quatro questões abertas, observamos a persistência de diversos conceitos enviesados sobre o que é uma aula de língua portuguesa e sobre qual a função das análises linguísticas em cursos de tecnologia e de licenciatura. Por intermédio das teorias de ensino de língua portuguesa recolhidas em Antunes (2003), Possenti (2006), Travaglia (2011), Bagno (2011) e Neves (2018) e tendo em vista a necessidade de uma prática docente dialógica (FREIRE, 1981, 2008; BAKHTIN, 2003), concluímos apontando que o melhor modo de garantir uma educação democrática é dar atenção às necessidades dos discentes, mas sem descuidar das necessidades teóricas para enfrentar os desafios da docência na educação profissional.

Palavras-chave: Educação profissional. Ensino-aprendizagem. Língua portuguesa. Didática.

Abstract: This paper has the function of presenting the results of research on the teaching of the Portuguese language in higher education courses at the IFSP (Federal Institute of São Paulo) Campos do Jordão campus whose focus is not that of language studies. Through the qualitative analysis of the answers given by the students to four open questions, we observed the persistence of several biased concepts about what a Portuguese language class is and about the role of linguistic analysis in technology and undergraduate courses. Through the theories of Portuguese language teaching collected in Antunes (2003), Possenti (2006), Travaglia (2011), Bagno (2011) and Neves (2018) and bearing in mind the need for a dialogical teaching practice (FREIRE, 1981, 2008; BAKHTIN, 2003), we conclude pointing out that the best way to guarantee a democratic education is to pay attention to the needs of students, but without neglecting the theoretical needs to face the challenges of teaching in professional education.
\end{abstract}

Keywords: Professional education. Teaching-Learning. Portuguese. Didacticism.

\section{Introdução}

Nosso trabalho consiste na apresentação de uma pesquisa sobre as avaliações que os/as estudantes dos cursos de ensino superior do Instituto Federal de Educação, Ciência e Tecnologia campus Campos do Jordão (IFSP - CJO) realizaram, de forma voluntária, acerca das disciplinas relacionadas à língua portuguesa cursadas no segundo semestre de 2019. Os discentes responderam a um questionário aberto, composto por quatro perguntas e direcionado àqueles e àquelas que se matricularam nas seguintes disciplinas: a) Comunicação e expressão, ministrada para o $1^{\circ}$ período do curso de Tecnologia em Análise e Desenvolvimento de Sistemas (TADS); b) Leitura, produção e interpretação de textos $I I$, ministrada para o $2^{\circ}$ período do curso de Licenciatura em Matemática (MAT); e c) Leitura e produção de textos, ministrada para o $2^{\circ}$ período do curso de Licenciatura em Pedagogia (PED).

\footnotetext{
* Professor de Língua Portuguesa do Instituto Federal de São Paulo (IFSP), campus Campos do Jordão, mestre e doutorando em Estudos Literários pela Universidade Estadual Paulista (UNESP - Araraquara). Coordena o projeto de extensão Inteligência Emocional e Docência, no IFSP-CJO, e é membro do Grupo de Pesquisa sobre Linguagem, Literatura e Educação (GPLLE/ IFSP) cadastrado pelo CNPq (dgp.cnpq.br/dgp/espelholinha/5304674409128290807919). E-mail: professorvalmirluis@ gmail.com.
} 
O objetivo geral dessa pesquisa é observar qual é a percepção dos alunos sobre a necessidade dos estudos de língua portuguesa em cursos de graduação diferentes daqueles como os de Letras, Linguística ou Estudos Literários, cujo foco é, por certo, o estudo das diversas formas de linguagem. Para nós, observar a percepção dos alunos é, de um modo ou de outro, perceber os próprios estudantes. É, mais ainda, compreender o jogo dialógico no qual se funda a tríade professor-estudante-objetos de conhecimento pelo viés dos estudantes e, com isso, talvez recordar a especificidade do trabalho docente - que se deve voltar mais para o outro ser humano, para o parceiro de ensinoaprendizagem, do que para conteúdos esvaziados de sentido. Em outras palavras, o objetivo é o de escutar os estudantes, pois "A escuta ativa e compreensiva leva, mais cedo ou mais tarde, a réplicas multifacetadas, plurais, que integrarão o fluxo dialógico, participando de sua composição." (AXT, 2006, p. 257).

Assim sendo, evocamos o dialogismo bakhtiniano observado por Faraco (2009, p. 42) que aponta que "a consciência individual se constrói na interação, e o universo da cultura tem primazia sobre a consciência individual. [...], já que Bakhtin entende o universo da cultura como um grande e infinito diálogo [...]". Ou seja,

Neste sentido pode-se dizer que o homem tem uma necessidade estética
absoluta do outro, do seu ativismo que vê, lembra-se, reúne e unifica que é o
único capaz de criar para ele uma personalidade externa acabada: tal
personalidade não existe se o outro não a cria. (BAKHTIN, 2003, p. 33)

E é precisamente nessa necessidade de escuta ativa e nesse jogo dialógico ético e estético - porque fundador de conceitos relacionais de si e do outro - da docência que as respostas que obtivemos podem contribuir ao considerar o corpo discente como fundamento e fim da ação docente e propor que, com o devido peso, as opiniões dos discentes sejam um parâmetro a mais utilizado para compor desde estratégias de ensino até o próprio projeto de cada uma dessas disciplinas no IFSP - CJO.

Nesse ponto, dentro das especificidades da educação profissional (EP) promovida pelos Institutos Federais (IFs), concordamos com Moura (2008, p. 32) que explica ser

fundamental que o docente tenha uma formação específica que lhe aproxime da problemática das relações entre educação e trabalho e do vasto campo da educação profissional e, em particular, da área do curso no qual ele está lecionando ou vai lecionar no sentido de estabelecer as conexões entre essas disciplinas e a formação profissional específica, contribuindo para a diminuição da fragmentação do currículo.

Não é este, obviamente, o caso da maior parte dos docentes que atuam nesse segmento educacional (MACHADO, 2008). Na prática, a falta de formação específica dos docentes para atuarem na EP muitas vezes descola os objetos de ensino daquilo que esse tipo de formação pleiteia. Não se entenda que há aqui a defesa de modelos tecnicistas de educação e um desprezo pela função. Pelo contrário, ao estender a voz aos discentes temos a crença de que a educação em um mundo VUCA "Volatile, Uncertain, Complex, Ambiguous" (HORNEY, PASMORE \& O'SHEA, 2010; BERNSTEIN, 2014), isto é, Volátil, Incerto, Complexo, Ambíguo é eminentemente dialógica, discursiva e responsiva. Em outras palavras, uma educação democrática na qual "o aluno ao final do processo possa ser autônomo" (MEIER; GARCIA, 2007, p. 193), sendo-o já durante o próprio processo de ensino-aprendizagem por intermédio de uma atuação segura de seus professores é o que acreditamos poder fomentar através da divulgação do que pensam os próprios discentes. 
Assim, nosso trabalho fornece alguns índices que possibilitam questionamentos sobre práticas de ensino, aprendizagem e avaliação e, em alguma medida, situam o espaço da língua portuguesa em cursos superiores de graduação que não são voltados especificamente para os estudos linguísticos. Para tal, discorreremos brevemente sobre os objetivos e as condições de utilização da abordagem qualitativa de pesquisa, passaremos por alguns sentidos do que aqui se toma por avaliação, explicitaremos os dados recolhidos e, por fim, faremos uma sucinta análise desses dados.

\section{Objetivos}

A fim de promover a interlocução com os principais interessados nas disciplinas cursadas, isto é, os estudantes, foram enviadas quatro questões abertas por e-mail institucional, através do Serviço Unificado de Administração Pública (SUAP), para os que se matricularam nas disciplinas referentes à comunicação em língua portuguesa no $2^{\circ}$ semestre de 2019, no IFSP-CJO, em TADS, MAT e PED.

Os e-mails foram enviados com cópia a cada um dos coordenadores destes cursos, nos dias 02 de abril e 04 de maio de 2020, a fim de que houvesse um afastamento temporal em relação à vivência da disciplina e as respostas fossem o menos enviesadas possíveis, já que o primeiro semestre de 2020 estava em marcha, e as respostas foram sendo tabuladas durante os meses de abril e maio de 2020. No corpo do e-mail, os discentes foram informados sobre: a) os objetivos da pesquisa, b) o resguardo do anonimato das respostas e c) o número ilimitado de caracteres para cada resposta. As questões enviadas foram as seguintes:

Tab. 1: Questões abertas

1. Qual a importância (ou a falta de importância) do ensino de língua portuguesa na graduação do IF?

2. O que foi bom, o que foi ruim? O que poderia melhorar para essa disciplina (que vocês tiveram no semestre passado) ser mais efetiva na vida profissional que vocês imaginam que terão?

3. Qual era a expectativa de vocês sobre a disciplina? Essas expectativas foram alcançadas, superadas ou frustradas? Você consegue ver motivos para isso?

4. Caso você fosse professor/a de língua portuguesa no IF, o que você necessariamente ensinaria? O que não ensinaria de jeito nenhum? Justifique.

Fonte: Elaboração do autor, 2020.

Através da análise interpretativa das respostas a essas perguntas, objetivamos compreender dois pontos fundamentais: 1) mesmo sendo de áreas que não são específicas do campo das Letras, os discentes que passaram pelas disciplinas já elencadas veem importância no aprendizado de língua portuguesa? Em que medida? e 2) Há diferença significativa entre a percepção colhida dos alunos dos cursos TADS, MAT e PED? Com a organização dessas respostas, acreditamos auxiliar na reflexão tanto da prática docente quanto da pertinência dos programas pedagógicos dos cursos em questão.

\section{Metodologia}

A presente pesquisa foi realizada por meio de uma abordagem qualitativa, já que este tipo de análise procura "compreender os fenômenos segundo a perspectiva dos sujeitos, ou seja, dos participantes da situação em estudo" (GODOY, 1995, p. 58). Essa abordagem justifica-se, ainda, pela preocupação que temos de trazer uma reflexão sobre 
as ações dos atores sociais envolvidos na realidade do IFSP - CJO, bem como as consequências dessas ações.

Em relação ao alcance de nossa pesquisa, obtivemos os seguintes resultados:

Tab. 2: Alcance da pesquisa

\begin{tabular}{|l|l|}
\hline $\begin{array}{l}\text { Quantidade total de alunos matriculados em } \\
\text { TADS, MAT e PED no IFSP-CJO: 79. }\end{array}$ & $\begin{array}{l}\text { Quantidade de alunos para os quais a pergunta foi } \\
\text { enviada via e-mail institucional: 79. }\end{array}$ \\
\hline $\begin{array}{l}\text { Quantidade de alunos menos os que trancaram: } \\
77 .\end{array}$ & Quantidade de respostas obtidas: 16. \\
\hline $\begin{array}{l}\text { Quantidade de alunos menos os reprovados por } \\
\text { falta: } 57\end{array}$ & $\begin{array}{l}\text { Porcentagem de alcance do questionário relativa } \\
\text { aos alunos aprovados: } 28,07 \%\end{array}$ \\
\hline
\end{tabular}

Fonte: Elaborado pelo autor com base em dados do SUAP.

Outra importante informação tem a ver com a quantidade relativa de respostas, tendo em vista que todos os que responderam ao questionário foram aprovados nas respectivas disciplinas. Assim:

Tab. 3: Total de alunos

\begin{tabular}{|l|l|l|l|}
\hline & TADS & MAT & PED \\
\hline Total de alunos matriculados & 20 & 25 & 34 \\
\hline Total de alunos aprovados & 8 & 20 & 28 \\
\hline
\end{tabular}

Fonte: Elaborado pelo autor com base em dados do SUAP.

Por mais que a porcentagem de alcance pareça baixa, isso já era esperado devido ao modelo de questionário de que nos valemos (MARCONI; LAKATOS, 2003). E confirmado pela afirmação de Richardson (1999, p. 102) de que o "objetivo fundamental da pesquisa qualitativa não reside na produção de opiniões representativas e objetivamente mensuráveis de um grupo; está no aprofundamento da compreensão de um fenômeno social [...]". Por isso a validade de uma pesquisa qualitativa não deve ser dada pelo tamanho da amostra recolhida, mas pela profundidade de seu desenvolvimento.

Para nós, mais ainda, longe de cairmos em um positivismo insípido ou de buscarmos um endeusamento de técnicas ou um formalismo estereotipado (TRIVIÑOS, 2009), o que nos interessa é a possibilidade de demonstrarmos um modelo possível de "escuta". Por isso é que, para Richardson (1999, p. 79), "A abordagem qualitativa de um problema, além de ser uma opção do investigador, justifica-se, sobretudo, por ser uma forma adequada para entender a natureza de um fenômeno social". Isso porque, de acordo com Skinner, Tagg e Holloway (2000), as técnicas qualitativas voltam-se principalmente para a experiência vivida das pessoas e buscam atribuir significados a estruturas, processos e/ou eventos inseridos em determinados cenários sociais.

Por certo, uma pesquisa como a nossa de natureza qualitativa, com um nível entre o explicativo e o descritivo e valendo-se da técnica do estudo de caso (SILVA, 2014), pode ser alvo de preconceitos teóricos por aqueles que, conforme mostra Campomar (1991, p. 96), "desconhecem o método e o consideram [...] pouco acadêmico. [E] por aqueles que acreditam ser verdadeiro somente aquilo que é quantificado.". Mas o mesmo autor, um pouco a frente, demonstrará que tais julgamentos são equivocados já em suas bases, pois "o método do caso não é fácil, já que quanto menos estruturada mais difícil a aplicação da metodologia de pesquisa e necessária maior dedicação acadêmica" (CAMPOMAR, 1991, p. 96). Quanto aos "quantitativistas", Campomar identificará uma grande quantidade de casos em que o uso de técnicas estatísticas é feito apenas para encobrir dados mal coletados e concluirá com base em Castro (1977) que "É melhor fazer uso sofisticado de uma técnica simples, em 
vez de procurar técnicas sofisticadas apenas porque estão disponíveis." (CAMPOMAR, 1991, p. 96).

Obviamente, este tipo de pesquisa não é isento de problemas. Como nos valemos de questionário com questões abertas, algumas desvantagens em nosso método são:
a) Percentagem pequena dos questionários que voltam.
[...]
d) Impossibilidade de ajudar o informante em questões mal compreendidas.
e) A dificuldade de compreensão, por parte dos informantes, leva a uma uniformidade aparente.
f) Na leitura de todas as perguntas, antes de respondê-las, pode uma questão influenciar a outra.
g) A devolução tardia prejudica o calendário ou sua utilização.
h) $\mathrm{O}$ desconhecimento das circunstâncias em que foram preenchidos toma difícil o controle e a verificação. [...] (MARCONI; LAKATOS, 2003, p. 202).

Ainda assim, o uso desse modelo de questão aberta em estudos de caso como o que propomos parece-nos bastante apropriado, pois, como afirma John Guerring em seu artigo What Is a Case Study and What Is It Good for?, os estudos de caso são geralmente mais úteis quando: 1) as inferências são descritivas e não causais; 2) a profundidade é valorizada; 3) as comparações internas têm precedência sobre as representatividades externas do caso; 4) a percepção dos mecanismos causais é mais importante que a dos efeitos causais; 5) a proposição causal em questão é invariante e não probabilística; 6) a estratégia de pesquisa é exploratória, e não confirmatória; e 7) a variação útil estiver disponível para apenas uma única unidade ou um pequeno número de unidades. (GUERRING, 2004).

Por isso, podendo definir um estudo de caso como "um estudo intensivo de uma única unidade com o objetivo de entender uma classe maior de (semelhantes) unidades." (GUERRING, 2004, p. 342, grifos do autor), então esta parece-nos a melhor abordagem para compreender e analisar as respostas que obtivemos.

\section{A "escuta" como fundamento teórico}

Por certo, quando falamos que queremos observar a percepção de estudantes em relação à efetividade ou não - do ponto de vista deles - de uma determinada disciplina, o que queremos é, de fato, escutá-los. Isso porque, conforme já anunciamos, buscamos nortear nosso trabalho por uma dimensão dialógica da interação, não monológica (BAKHTIN, 2003), isto é, não voltada para um discurso docente autoritário e impeditivo, mas, sim, democrático e aberto a ouvir os diferentes atores sociais do processo educativo.

Escutar, dessa forma, é o fundamento da educação que acreditamos ser verdadeiramente transformadora. No entanto, na impossibilidade metodológica de escutar, de fato, o que diriam os alunos, optamos por ofertar-lhes a possibilidade de responderem a perguntas abertas não limitadas por alternativas excludentes entre si ou por limites espaciais para o desenvolvimento do texto. Assim é que podemos associar a leitura que fazemos da escrita livre das respostas dos estudantes ao pressuposto de Paulo Freire (2008, p. 88), para quem "é ouvindo o educando, tarefa inaceitável pela educadora autoritária, que a professora democrática se prepara cada vez mais para ser ouvida pelo educando". 
Por isso, ainda que nosso processo de "escuta" esteja mediado pelas capacidades de produção escrita dos estudantes, é essa concepção de diálogo que permeia todo nosso trabalho, pois acreditamos na interdependência e na co-dependência como princípios fundamentais que precisam estar na base do processo de ensino-aprendizagem. Na concepção de Freire (1981, p. 93, grifo do autor), "Ninguém pode dizer a palavra verdadeira sozinho [...]. O diálogo é este encontro dos homens, mediatizados pelo mundo, para pronunciá-lo, não se esgotando, portanto, na relação eu-tu”. Com efeito, não um diálogo estruturado como uma conversa aleatória e despretensiosa, mas como ato interacional em que necessariamente há uma escuta atenta e respeitosa. Assim, ainda que por escrito, o que propomos é dialógico. Até porque

Uma atividade é interativa quando é realizada, conjuntamente, por duas ou mais pessoas cujas ações se interdependam na busca dos mesmos fins. Assim, numa inter-ação ("ação entre"), o que cada um faz depende daquilo que o outro faz também: a iniciativa de um é regulada pelas condições do outro, e toda decisão leva em conta essas condições. Nesse sentido, a escrita é tão interativa, tão dialógica, tão dinâmica e negociável quanto a fala. (ANTUNES, 2003, p. 45)

Enfim, como nossa proposta de estudo não se restringe à confirmação de uma teoria, mas busca a mobilização de um debate dentro do qual os discentes sejam uma das vozes consideradas, entendemos que o estudo de caso proposto com base nas respostas dadas às quatro questões abertas formuladas seja o método mais eficaz para a compreensão mais profunda dos "comos?" e "por quês?", isto é, das respostas e das avaliações dadas pelos discentes.

\section{Como e por que avaliar?}

Antes de observar a produção escrita dos estudantes em questão, é necessário compreender sob que prisma entendemos a validade da avaliação discente como parâmetro influente na agenda da educação em EPs como os IFs, uma vez que, como afirma Cabrito (2009, p. 197), “Avaliar a qualidade em educação é indispensável, na medida em que só a partir dessa avaliação se podem propor práticas conducentes a melhorar aquela qualidade [...]". E complementa que, não obstante, a "avaliação deve servir para que cada escola encontre o seu caminho e não para promover concorrência, rivalidade, discriminação, num claro processo de reprodução das exclusões e das desigualdades sociais.” (CABRITO, 2009, p. 198).

Por isso, quando os discentes avaliam o processo educacional pelo qual passaram, têm condições de tentar elaborar os aspectos sociais dentro dos quais eles estão inseridos, o que implica pensar a si mesmos como sujeitos do saber, dotados de potencialidades que, com alguma parcimônia, os docentes e as próprias instituições podem usar em prol da formação destes mesmos estudantes. É isso, pelo menos, que ensina Irandé Antunes em seu Aula de português quando - partindo dos estudos de Mary A. Kato, em No mundo da escrita: uma perspectiva psicolinguística -, sustenta o "princípio de que é o aluno o sujeito da aprendizagem que acontece, ou seja, é ele quem realiza, na interação com o objeto de aprendizagem, a atividade estruturadora da qual resulta o conhecimento [...]" (ANTUNES, 2003, p. 43, grifo da autora).

Ampliando em termos gerais de política educacional, para nós a atual noção de avaliação tem estreita relação com a obra do sociólogo e político britânico Michael Young que em seu The rise of the meritocracy, 1870-2033: an essay on education and 
equality, publicado pela primeira vez em 1958, anuncia uma sociedade distópica em que a elite constitui-se por pessoas que foram expostas a testes padronizados de inteligência (Q.I.) e conseguiram bons resultados. Na satírica obra de Young, ainda muito mal entendida (ALLEN, 2011; ROCHA, 2017; ECONOMIST, 2018), a "meritocracia" não passa de um disfarce, uma vez que aqueles que têm acesso às escolas que se dedicam a preparar seus estudantes para os exames de inteligência, via de regra, conseguem alcançar os primeiros lugares, mantendo, assim, a desigualdade social.

Dessa forma, "da procura das escolas eficazes à produção de rankings, [...] da avaliação institucional aos orçamentos competitivos, a avaliação tornou-se o cerne da política educacional" (LIMA, 2015, p. 1341). O ponto crítico, no entanto, não está na avaliação, mas na relação direta que se quer entre os resultados das avaliações e a "meritocracia", pois, nesse contexto, as melhores escolas são as mais bem avaliadas interna e externamente e, justamente por isso, as que recebem os/as alunos/as também mais bem avaliados/as, quer seja por terem passado por rigorosos processos seletivos para os quais foram amplamente preparados - quer seja por questões socioculturais inerentes à formação familiar (BORDIEU, 1998), o que, por sua vez, dá continuidade ao ciclo. Ou seja, alunos com condições econômicas, sociais e culturais mais altas do que a média buscam escolas bem avaliadas que os preparem para os exames de outras escolas e/ou universidades mais bem avaliadas ainda. Naturalmente, esse é um sistema que se retroalimenta.

A avaliação, então, acaba sendo também uma instituição de poder que legitima as desigualdades ao fazer com que a ideia de "meritocracia", no sentido amplo do termo, associe-se à ideia de que "a civilização não depende da massa tola, do homem médio, mas da minoria criativa, do inovador que com um golpe pode salvar dez mil empregos. [...]" (YOUNG, 1961, p. 15). Nesse sentido é que, na análise de Piza (1985, p. 2014), para Young, a meritocracia funciona como uma classe social que "se aperfeiçoa e se destaca dos demais capitalistas e que também coopta os principais líderes e os mais capazes das classes inferiores, principalmente através da educação, com a função e a necessidade de desenvolver o capitalismo enquanto capitalismo."

Não é, no entanto, essa a intenção que tivemos ao propor que os discentes avaliassem a disciplina cursada. Pelo contrário, nossa pesquisa instituiu-se imbuída de um sentimento de interação ativa (AXT, 2006), a fim de que possamos realmente pensar sobre os rumos do ensino de língua portuguesa não só pelos ditames da "meritocracia" mercadológica que subjaz à construção dos planos de curso "com a função e a necessidade de desenvolver o capitalismo enquanto capitalismo", nem apenas pelo saber acadêmico que sustenta a atuação docente, mas também pela experiência dos sujeitos aprendizes.

Resta lembrar que os sujeitos discentes que efetuaram a avaliação que propusemos são, talvez, justamente aqueles que, de uma forma ampla, podem contribuir de modo decisivo para desconstruir a noção de meritocracia que apresentamos e criticamos anteriormente. Isso porque sendo "equiparados às universidades federais" (BRASIL, 2008), do ponto de vista do espaço ocupado pelos Institutos Federais (IFs) na estrutura acadêmica brasileira, essas instituições e os sujeitos que a compõem já nasceram "com uma identidade mais próxima da sociedade brasileira como um todo." (RISTOFF, 2014, p. 744), pois, por exemplo, em relação à lei 12.711, de 29 de agosto de 2012 - a Lei das Cotas -, " $83 \%$ dos institutos [federais] já no primeiro ano de vigência passaram a cumprir a meta prevista para 2016 [de ter 50\% de estudantes oriundos de escolas públicas] contra apenas 34\% das universidades" (RISTOF, 2014, p. 744). Isso explicaria, em tese, a necessidade mais premente ainda de se dar atenção ao 
que diz o corpo discente dos IFs, uma vez que ele é formado em boa parte por aqueles que historicamente são excluídos das instâncias de poder no Brasil. Observe-se o que diz a Lei:

Art. $1^{\circ}$ As instituições federais de educação superior vinculadas ao Ministério da Educação reservarão, em cada concurso seletivo para ingresso nos cursos de graduação, por curso e turno, no mínimo $50 \%$ (cinquenta por cento) de suas vagas para estudantes que tenham cursado integralmente o ensino médio em escolas públicas.

Parágrafo único. No preenchimento das vagas de que trata o caput deste artigo, $50 \%$ (cinquenta por cento) deverão ser reservados aos estudantes oriundos de famílias com renda igual ou inferior a 1,5 salário-mínimo (um salário-mínimo e meio) per capita. [...] (BRASIL, 2012).

Dessa maneira, a avaliação dos cursos em questão, realizada pelos alunos que vivenciaram a experiência no decorrer dessas disciplinas, tanto nos dá indicadores da percepção desses estudantes em relação à importância ou não de tais objetos de ensino para suas trajetórias profissionais e pessoais quanto nos esclarece, no subtexto, a relação sujeito-mundo condensada nas respostas dadas por todos e cada um.

\section{Conteúdo programático}

Aqui, com a intenção de que seja possível balizar as respostas dos alunos dentro de cada curso e entre os cursos, vale a pena observar o conteúdo programático proposto por cada plano de curso e as relações de aproximação e afastamento que eles mantêm entre si.

Tab. 4: Conteúdo programático de Língua portuguesa

\begin{tabular}{|c|c|c|}
\hline $\begin{array}{l}\text { COMUNICAÇÃO } \\
\text { EXPRESSÃO (TADS) }\end{array}$ & $\begin{array}{l}\text { LEITURA, PRODUÇÃO E } \\
\text { INTERPRETAÇÃO DE TEXTO } \\
\text { II (MAT) }\end{array}$ & $\begin{array}{l}\text { LEITURA E PRODUÇÃO } \\
\text { DE TEXTOS (PED) }\end{array}$ \\
\hline do progran & Conteúdo programático & о \\
\hline $\begin{array}{l}\text { 1. Teoria da comunicação. } \\
\text { 2. Comunicação estratégica. } \\
\text { 3. Linguagem verbal e não } \\
\text { verbal. } \\
\text { 4. Técnicas de leitura. } \\
\text { 5. Fichamento, resumos e } \\
\text { resenhas. } \\
\text { 6. Interpretação de textos. } \\
\text { 7. Estrutura do texto oral e } \\
\text { escrito. } \\
\text { 8. Regras gramaticais. } \\
\text { 9. Descrição e argumentação. } \\
\text { 10. Introdução à história da } \\
\text { cultura afro-brasileira } \\
\text { indígena e e influência } \\
\text { sociocultural na comunicação e } \\
\text { expressão. }\end{array}$ & $\begin{array}{l}\text { 1. Organização do texto escrito de } \\
\text { natureza técnica, científica e } \\
\text { acadêmica: características da } \\
\text { linguagem técnica, científica e } \\
\text { acadêmica; } \\
\text { 2. Leitura e produção de resumo, } \\
\text { resenha, relatório e artigo } \\
\text { científico; } \\
\text { 3. Estudo do resumo científico; } \\
\text { 4. Linguagem pessoal e } \\
\text { impessoal; } \\
\text { 5. Aspectos da produção textual: } \\
\text { ambiguidade, } \\
\text { pontuação; } \\
\text { 6. Argumentação e estratégias } \\
\text { argumentativas; } \\
\text { 7. Educação Ambiental; Política } \\
\text { Nacional de Resíduos Sólidos, } \\
\text { Diretrizes para o Saneamento } \\
\text { Básico e a Política Nacional de } \\
\text { Saneamento Ambiental, e, Lei dos } \\
\text { Crimes Ambientais; }\end{array}$ & $\begin{array}{l}\text { 1. Linguagem e comunicação } \\
\text { 1.1. Linguagem verbal e não } \\
\text { verbal; } \\
\text { 1.2. Gêneros do discurso; } \\
\text { 1.3. Modos de organização do } \\
\text { discurso; } \\
\text { 1.4. Organização do texto } \\
\text { escrito e suas características; } \\
\text { 1.5. Organização do texto } \\
\text { escrito de natureza técnica, } \\
\text { científica e acadêmica: } \\
\text { características da linguagem } \\
\text { técnica, científica } \\
\text { acadêmica; e } \\
\text { 1.6. Leitura e produção de } \\
\text { resumo, resenha, relatório e } \\
\text { artigo científico; } \\
\text { 1.7. Coerência e coesão; } \\
\text { 1.8. Linguagem pessoal e } \\
\text { impessoal; } \\
\text { 1.9. Registros de linguagem; } \\
\text { Variação linguística }\end{array}$ \\
\hline
\end{tabular}




\begin{tabular}{|c|c|c|}
\hline & $\begin{array}{l}\text { 8. Relações étnico-raciais e } \\
\text { história e cultura Afro-Brasileira e } \\
\text { Indígena; } \\
\text { 9. Dinâmicas de grupo e } \\
\text { elaboração de seminários; } \\
\text { 10. Norma culta da língua } \\
\text { portuguesa: regência, crase, } \\
\text { emprego de pronomes oblíquos. }\end{array}$ & $\begin{array}{l}\text { 2. Dinâmicas de grupo e } \\
\text { elaboração de seminários. } \\
\text { 3. Norma culta da língua } \\
\text { portuguesa: pontuação; crase; } \\
\text { concordância e regência } \\
\text { verbais e nominais; verbos: } \\
\text { flexões; ortografia } \\
\text { acentuação gráfica; período } \\
\text { composto. } \\
\text { 4. Leitura e produção de } \\
\text { textos sobre educação } \\
\text { ambiental. }\end{array}$ \\
\hline $\begin{array}{l}\text { Total de aulas: } 40 \\
\text { Total de horas: } 33,3\end{array}$ & $\begin{array}{l}\text { Total de aulas: } 40 \\
\text { Total de horas: } 33,3\end{array}$ & $\begin{array}{l}\text { Total de aulas: } 80 \\
\text { Total de horas: } 66,6\end{array}$ \\
\hline
\end{tabular}

Fonte: Elaborado pelo autor com base em dados disponíveis em <https://www.ifspcjo.edu.br/>.

Para além de elementos "estranhos" à língua portuguesa, como o conteúdo $10 \mathrm{de}$ TADS, os conteúdos 7 e 8 de MAT e o conteúdo 4 de PED - os quais, aliás, parecem compor os conteúdos programáticos apenas como uma forma de "cumprir a lei", no caso a Lei federal 10.639/03 e a Resolução CNE/CP no 2/2012, e não como instrumentos que realmente sejam capazes de suscitar, de forma organizada, a reflexão sobre a prática de linguagem dentro dos contextos específicos a que se referem -, queremos destacar e comentar alguns pontos da estruturação dos conteúdos programáticos, com o fito de auxiliar na interpretação das respostas produzidas pelos estudantes e aqui apresentadas e, além disso, para colocar nosso posicionamento crítico em relação a alguns desses conteúdos e sua importância para o conceito de educação profissional que já destacamos.

No caso de TADS, apesar de ser um curso cujo foco são os "sistemas", não há menção à ideia de "sistema linguístico" ou algo que o valha no conteúdo definido no programa do curso. No entanto, há uma espécie de privilégio da língua portuguesa instrumental, isto é, a língua que se vai usar para fazer algo com ela. Nesse sentido, conteúdos genéricos como "2. Comunicação estratégica" e "8. Regras gramaticais" serão parte do plano de aula do docente, com maior ou menor frequência, a depender principalmente da relação que a maior parte dos componentes da sala tenham com os usos da língua. Para nós, a fim de que os estudos de língua portuguesa fossem mais justificáveis, deveriam ser incluídos como conteúdo de trabalho recursos tais quais a pragmática linguística e a análise de discursos, bem como discutir efeitos de sentido na produção de gêneros textuais do mundo do trabalho e organizar discursos orais mais ou menos objetivos e subjetivos em interações verbais presenciais e/ou virtuais, por exemplo, a fim de que realmente houvesse uma ligação entre a língua portuguesa, a reflexão social que estes estudantes precisam desenvolver e o mundo do trabalho para o qual eles se encaminham, tal qual preconizam práticas de didática de língua portuguesa como as de Antunes (2003), Possenti (2006), Travaglia (2011), Bagno (2011) e Neves (2018), guias fundamentais de toda a reflexão sobre ensino de português aqui proposta.

Para MAT, apesar de poder colocar como conteúdo programático a reflexão sobre o uso de símbolos e de representações nas diversas linguagens, entre elas a língua portuguesa e a matemática, pouco há, também, de reflexão e muito de instrumentalização. Neste caso, uma espécie de "livro de regras" de como se escrever um artigo científico. Do modo como os conteúdos são apresentados, a função docente parece não corresponder ao desejos do curso, sendo talvez mais efetivo que, ao invés de uma aula regular, o tempo da aula fosse disponibilizado para correções individuais, ou em pequenos grupos, de textos científicos que estivessem sendo escritos pelos discentes. 
No entanto, mesmo que essa fosse a "solução" encontrada, o fato de a disciplina em questão ser ofertada no segundo semestre da licenciatura em matemática traz os problemas da imaturidade discente e da falta de conhecimentos técnicos da área como barreiras à construção de um trabalho científico adequado. Assim, a fim de cumprir o programa proposto, tal disciplina deveria ser deslocada no tempo do curso, passando a figurar no quarto ou no sexto semestres. Tendo, por outro lado, o foco da disciplina voltado para a formação de professores talvez fosse mais proveitoso concentrar-se na organização dos argumentos, na análise de discursos e nas interações pragmáticas. Vale atenção também o, no mínimo, peculiar conteúdo 9, que parece indicar um modelo de como conduzir a aula e/ ou a avaliação muito mais do que um conteúdo programático propriamente.

Já para PED, em que pese o "conteúdo" 2 - cuja crítica é a mesma que fizemos ao item 9 de MAT -, há uma melhor distribuição entre conteúdos técnicos de instrumentalização gramatical e conteúdos práticos e pragmáticos. A crítica, então, fica mais ao tempo disponibilizado para o estudo desses conteúdos, pois a disciplina em questão restringe-se ao segundo semestre do curso superior de pedagogia do IFSP-CJO. Tendo em vista o foco desse curso superior, no entanto, tal quantidade de horas disponibilizadas para a disciplina de Leitura e produção de textos não deveria ser um problema, mas o é, principalmente por conta de deficiências na formação básica dos aspirantes a professores e professoras. Pelo menos é isso o que as pesquisas mais recentes apontam

\footnotetext{
Nenhum estado brasileiro escapa de um diagnóstico negativo que ajuda a explicar a baixa qualidade da educação no país: estudantes que almejam se tornar professores têm desempenho acadêmico pior do que a média dos demais futuros profissionais. [...]

"Esses dados mostram que o perfil dos alunos que atraímos para o magistério se tornou um problema sério", diz Laura Machado, especialista em educação na cátedra do Instituto Ayrton Senna no Insper. (FRAGA, 2019, s/p).
}

Com isso, fica clara a necessidade de se repensar o lugar do ensino de língua portuguesa nos cursos superiores do IF, superando a mera instrumentalização asséptica que pouco possibilita a formação crítica dos estudantes e, ao mesmo tempo, enfrentando a relativamente baixa proficiência no uso do idioma por futuros docentes.

\section{Análise dos dados}

Valendo-nos de técnicas discursivas de análise (FAIRCLOUGH, 2008; KOCH, 2004; ORLANDI, 2009; CHARAUDEAU, 2011; HERACLEOS, 2006), mantivemos ao máximo a expressão original dos textos produzidos pelos estudantes, por isso os cortes nas respostas foram marcados pelo sinal "[...]". Para melhorar a apresentação, organizamos as respostas obtidas em diferentes quadros, buscando associá-las a valores abrangentes que emergem do próprio discurso materializado nas respostas dos discentes. A fim de manter o sigilo, cada estudante será representado pela letra $E$ seguida de um numeral - sempre o mesmo para o/a mesmo/a estudante - e separada por uma barra indicativa do curso a que o respondente está vinculado. Dessa forma, teremos: E1, E2 e E3, como discentes de TADS; E4, E5, E6 e E7, MAT; e E8, E9, E10, E11, E12, E13, E14, E15 e E16, PED.

Assim, para a questão 1 (Qual a importância (ou a falta de importância) do ensino de língua portuguesa na graduação do IF?), tudo girava em torno da 
consideração e do apreço dos estudantes pelos estudos de língua portuguesa mesmo após os anos de ensino básico. Dessa forma, classificamos como "muito importante" as respostas que intensificavam a importância do ensino por meio de expressões com função adjetiva ou adverbial, como "fundamental", "super" e "importantíssimo". Respostas mais neutras, que reafirmavam a importância desse ensino foram classificadas como "importante".

As respostas obtidas demonstram que todos os estudantes creem que o ensino de língua portuguesa seja importante em suas formações. Apenas E6: "porquê iremos fazer parte da academia"; E7: "é importante [...] saber interpretar problemas para a resolução de exercícios"; E14: "Nossa Língua Portuguesa é a nossa mãe, devemos conhece la bem se quisermos ser bons profissionais"; e E16: "O ensino da língua portuguesa nos cursos superiores é importante" responderam que a disciplina era "importante", enquanto todos os outros apontaram que a disciplina deveria ser considerada como "muito importante" para a formação de cada um deles.

Alguns fatos chamam a atenção: a) todos os discentes de TADS, um curso da área tecnológica, acreditam que a língua portuguesa seja "muito importante" na graduação; b) contrariando o senso comum, estudantes de MAT não têm dúvida sobre a importância da língua portuguesa em sua formação, com E7 lembrando, inclusive, que o estudo de interpretação de textos pode auxiliar "na resolução dos exercícios"; c) para os estudantes de PED, o estudo de língua portuguesa é associado à prática docente que será por eles mesmos realizada, como, por exemplo, demonstra E11: "eu acho de extrema importância [...] e muito especial no nosso curso"; d) a resposta de E13, "é importantíssimo o ensino desta disciplina, principalmente para nós que não tivemos um ensino médio completo", sugere o potencial que um curso do IF, como o de Pedagogia, tem de trazer para a "academia" pessoas que costumeiramente não fariam parte desse grupo. Este potencial de abrangência é tanto algo a ser louvado, pois traz consigo um forte componente de fortalecimento de identidades marginalizadas, quanto é um desafio para os docentes que, com frequência, precisam repensar os métodos de aplicação do programa da disciplina, a fim de que haja o mínimo de evasão e de baixo aproveitamento possível daqueles que ingressaram nos respectivos cursos.

Isso se torna importante, visto que os estudantes de TADS estão apenas no primeiro semestre do curso; e os de MAT e PED, apenas no segundo semestre. Mas tem uma carga mais importante ainda para a compreensão de qual a dimensão de estudos linguísticos que precisamos levar para a sala de aula. A saber: aquela em que o texto em sua dimensão discursiva, isto é, inserido numa situação concreta de enunciação, servindo a um determinado fim - que pode, este sim, ser avaliado, mensurado e qualificado -, seja o mediador das interações entre os interlocutores. (POSSENTI, 2006; BAGNO, 2011).

A questão 2 ( $O$ que foi bom, o que foi ruim? O que poderia melhorar para essa disciplina (que vocês tiveram semestre passado) ser mais efetiva na vida profissional que vocês imaginam que terão?), apesar de deixar muito claro o que se espera como resposta, isto é, fatores "positivos" - agrupados no signo "bom" -, os "negativos" agrupados como "ruim" - e os que "poderiam melhorar", abre espaço para os pensamentos mais amplos que os discentes possam ter em relação ao mercado de trabalho que os espera. Além disso, por trazer três itens dentro de sua composição, a depender do tempo ou da atenção que os estudantes dispensaram para confeccionar as respostas, ao menos um dos três pontos pode ter passado despercebido.

As respostas obtidas foram as seguintes:

Quadro 1: Sobre o nível de efetividade da disciplina 


\begin{tabular}{|c|c|c|c|}
\hline \multirow{2}{*}{$\begin{array}{l}\text { ESTUDANTE/ } \\
\text { CURSO }\end{array}$} & \multicolumn{3}{|c|}{ QUESTÃO 2} \\
\hline & BOM & RUIM & $\begin{array}{c}\text { PODE } \\
\text { MELHORAR }\end{array}$ \\
\hline E1/ TADS & $\begin{array}{l}\text { Achei excelente aulas } \\
\text { práticas [...] que } \\
\text { simulavam a vida real, } \\
\text { como no exemplo de uma } \\
\text { entrevista de emprego. }\end{array}$ & & $\begin{array}{l}\text { Acredito que a melhor } \\
\text { forma de entender a } \\
\text { matéria seja utilizar } \\
\text { exemplos em que ele } \\
\text { possa ver o quanto } \\
\text { aquilo é um benefício } \\
\text { para ele [...] eu } \\
\text { indicaria que ele fizesse } \\
\text { até mais disso. }\end{array}$ \\
\hline E2/ TADS & & $\begin{array}{l}\text { Alguns professores somente } \\
\text { joga muita informação, } \\
\text { textos e muita gramatica } \\
\text { não explica muito onde vao } \\
\text { utilizar todas as coisas } \\
\text { ensinadas na matéria. }\end{array}$ & \\
\hline E3/ TADS & $\begin{array}{l}\text { Excelente em formação de } \\
\text { metodologias de estudo } \\
\text { [...], acesso a uma rotina } \\
\text { de aprofundamento } \\
\text { gramatical. }\end{array}$ & $\begin{array}{l}\text { Ter deixado a disciplina } \\
\text { para trás, sendo que em } \\
\text { períodos } \\
\text { teremos posteriores } \\
\text { relacionadas à projetos. }\end{array}$ & $\begin{array}{l}\text { Acredito que ampliação } \\
\text { de horário favoreceria } \\
\text { as dinâmicas que } \\
\text { realizamos. }\end{array}$ \\
\hline E4/ MAT & $\begin{array}{lrr}\text { Reflexões sobre } & \text { a } \\
\text { necessidade de uma } \\
\text { renovação nos métodos de } \\
\text { ensino atuais e o ensino } \\
\text { de técnicas } \\
\text { argumentação. }\end{array}$ & $\begin{array}{l}\text { Revisão das bases da } \\
\text { matéria e de conteúdos que } \\
\text { foram passados no semestre } \\
\text { anterior. }\end{array}$ & $\begin{array}{l}\text { Dedicar algumas aulas } \\
\text { a mais para analisar os } \\
\text { modelos de escrita de } \\
\text { artigos acadêmicos. }\end{array}$ \\
\hline E5/ MAT & $\begin{array}{l}\text { Aprender a desenvolver } \\
\text { textos. }\end{array}$ & $\begin{array}{l}\text { Falta de tempo para ler } \\
\text { todos os artigos. }\end{array}$ & $\begin{array}{l}\text { Ter } 3 \text { semestres de } \\
\text { lingua portuguesa. }\end{array}$ \\
\hline E6/ MAT & 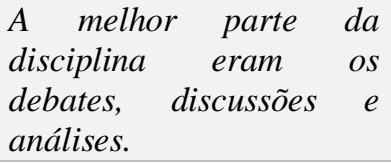 & $\begin{array}{l}\text { Não gostei tanto do foco } \\
\text { principalmente } \\
\text { gramática, porém eu } \\
\text { compreendo a importância. }\end{array}$ & $\begin{array}{l}\text { Poderia ser mais focada } \\
\text { em produção de textos } \\
\text { científicos. }\end{array}$ \\
\hline E7/ MAT & $\begin{array}{l}\text { As aulas de língua } \\
\text { portuguesa foram ótimas } \\
\text { principalmente na parte } \\
\text { da gramática. Achei bem } \\
\text { legal fazer o podcast [...] }\end{array}$ & $\begin{array}{l}\text { Acho que não teve aulas } \\
\text { suficientes para tirar todas } \\
\text { as dúvidas sobre a } \\
\text { resolução do artigo. }\end{array}$ & $\begin{array}{l}\text { Poderia ter um foco } \\
\text { maior na produção de } \\
\text { texto, principalmente na } \\
\text { construção de um } \\
\text { artigo. }\end{array}$ \\
\hline E8/ PED & $\begin{array}{l}\text { Foi muito bom ter a } \\
\text { revisão de regras e } \\
\text { entender como elas } \\
\text { funcionam e entender que } \\
\text { elas fazem sentido e } \\
\text { carregam sentido. }\end{array}$ & & $\begin{array}{l}\text { Gostaria que além de } \\
\text { matéria obrigatória, } \\
\text { fosse uma matéria } \\
\text { optativa [...], gostaria } \\
\text { de apreciar mais a } \\
\text { literatura nas aulas. }\end{array}$ \\
\hline E9/ PED & $\begin{array}{l}\text { Acredito que evolui na } \\
\text { forma que escrevia, para } \\
\text { mim foi muito bom. }\end{array}$ & $\begin{array}{l}\text { Acho que apenas um } \\
\text { semestre dessa matéria a } \\
\text { torna muito corrida. }\end{array}$ & \\
\hline E10/ PED & $\begin{array}{l}\text { O foco era a turma } \\
\text { apreender o conteúdo. }\end{array}$ & $\begin{array}{l}\text { Não consigo ter alguma } \\
\text { visão negativa, se não pela } \\
\text { estrutura da sala de aula rs. }\end{array}$ & \\
\hline E11/ PED & $\begin{array}{l}\text { Eu sempre tive muito } \\
\text { dificuldade em entender } \\
\text { as regras gramaticais, e } \\
\text { durante o semestre } \\
\text { passado aprendi diversos } \\
\text { assuntos que passei minha } \\
\text { vida academica tentando }\end{array}$ & & $\begin{array}{l}\text { Acho que a parte ruim é } \\
\text { que é apenas um } \\
\text { semestre para o ensino } \\
\text { da língua portuguesa é } \\
\text { muito pouco. }\end{array}$ \\
\hline
\end{tabular}




\begin{tabular}{|c|c|c|c|}
\hline & $\begin{array}{l}\text { compreender }[. . .] \text { pude } \\
\text { melhorar um pouco minha } \\
\text { escrita. }\end{array}$ & & \\
\hline E12/ PED & $\begin{array}{l}\text { Todas as atividades } \\
\text { propostas foram válidas, } \\
\text { principalmente porque } \\
\text { todas foram corrigidas e } \\
\text { tiveram um retorno } \\
\text { (comentários } \\
\text { professor) para os alunos. }\end{array}$ & & $\begin{array}{l}\text { Precisamos de mais } \\
\text { aulas, mais um semestre } \\
\text { dessa disciplina, e os } \\
\text { alunos que tinham mais } \\
\text { dificuldade precisavam } \\
\text { ter se acostumado como } \\
\text { ritmo da graduação. }\end{array}$ \\
\hline E13/ PED & $\begin{array}{l}\text { Com certeza conhecer } \\
\text { melhor estes conteúdos } \\
\text { que nem fazia idéia rs. }\end{array}$ & $\begin{array}{l}\text { Ruim foi o tempo curto } \\
\text { demais para se passar em } \\
\text { alguns meses. }\end{array}$ & \\
\hline E14/ PED & $\begin{array}{l}\text { Pude aprender muitas } \\
\text { coisas que não aprendi no } \\
\text { ensino médio. }\end{array}$ & $\begin{array}{lrr}\text { Se pudesse } & \text { termos ido a } \\
\text { museu } & \text { da } & \text { Língua } \\
\text { Portuguesa } & & \text { [...] termos } \\
\text { contato } & \text { com } & \text { mais } \\
\text { escritores. } & & \end{array}$ & \\
\hline E15/ PED & $\begin{array}{l}\text { O bom desta matéria foi } \\
\text { para relembrar o } \\
\text { português da escola. }\end{array}$ & $\begin{array}{l}\text { O ruim foi ter somente um } \\
\text { semestre para poder } \\
\text { reaprender. }\end{array}$ & $\begin{array}{l}\text { Deveria ter no mínimo } \\
\text { dois semestres. }\end{array}$ \\
\hline E16/ PED & $\begin{array}{l}\text { Retomou conceitos } \\
\text { básicos da língua } \\
\text { portuguesa, fez revisões } \\
\text { gramaticais, o que não é } \\
\text { função do ensino } \\
\text { superior, mas sem o fazê- } \\
\text { lo seria inviável } \\
\text { prosseguir. }\end{array}$ & $\begin{array}{l}\text { Sensação de incompetência, } \\
\text { ignorância, despreparo, } \\
\text { que consequentemente nos } \\
\text { deixa desanimados, e até } \\
\text { mesmo desesperados. É um } \\
\text { sentimento vergonhoso não } \\
\text { conseguir produzir um bom } \\
\text { texto. }\end{array}$ & $\begin{array}{l}\text { Seria necessária uma } \\
\text { carga horária maior } \\
\text { dessa disciplina, ou o } \\
\text { oferecimento de cursos } \\
\text { rápidos para atender } \\
\text { aqueles necessitam } \\
\text { desse suporte extra. }\end{array}$ \\
\hline
\end{tabular}

Fonte: Elaboração do autor, 2020.

Essa questão, do ponto de vista da EP e da avaliação que já discutimos é a mais densa. Em relação às respostas colhidas de TADS vê-se que E2 talvez tenha generalizado demais a questão, ao falar de "alguns professores". Mesmo assim, percebese seu desconforto com uma possível falta de relação entre teoria e prática, fator que Antunes (2003, p. 39-41) já demonstrara como sendo um dos problemas das muitas aulas de português no Brasil. E1 e E3, por sua vez, não só veem pontos positivos na disciplina, tais quais aproximação com a "prática" e "sistematização de uma rotina de estudos", como também acreditam que tais procedimentos devem ser reforçados e ampliados. Essa distinção de julgamento entre E2 e E1/ E3, muitas vezes tem origem na vida escolar pregressa desses sujeitos. Pelo modo como organiza seu discurso, nota-se uma provável necessidade de fundamentos mais básicos de língua portuguesa para E2, diferentemente de E1 e E3. Fatores como crença de incapacidade de aprendizagem por parte do discente, por vezes são mascarados quando este se encontra num nível de exigência superior ao que ele poderia responder no momento e passam despercebidos pelo docente que, muitas vezes, só consegue perceber o que se passou quando tem acesso a respostas individuais como as que propusemos aqui.

As respostas de MAT também trazem pontos interessantes. Foram, por exemplo, os únicos a responder os três itens da questão e trouxeram pontos de divergência. E5, por exemplo, acredita que o ponto alto da disciplina foi "aprender a desenvolver textos", mas E6 e E7 discordam, apontando justamente o "desenvolvimento de textos" como fator a ser melhorado no curso. As revisões gramaticais foram entendidas como ponto positivo para E7, porém E4 e E6 viram este mesmo ponto como o fator negativo do curso. E4, E6 e E7 entenderam como positiva a dinâmica didática construída por meio 
de debates e de podcasts, mas, por outro lado, E4, E6 e E7 viram como ponto a melhorar a falta de foco na construção de um artigo científico.

Tais divergências podem demonstrar a dificuldade que os docentes têm de enfrentar ao lidar com distintas expectativas dos discentes dentro de uma mesma sala de aula. Mas ao mesmo tempo sugerem que o reconhecimento dos discentes em relação ao uso de metodologias mais interativas, com foco na construção dos sujeitos de forma integral, esbarra numa concepção de ensino de língua portuguesa mais voltado para o tecnicismo e para as fórmulas estruturais de construção de gêneros de texto específicos. Nesse ponto, cumpre lembrar que talvez haja uma dificuldade nos discentes em descolar a língua portuguesa de uma função prescritiva que lhe foi atribuído desde há muito. Por essa via, ao invés de reflexões sobre os usos e as consequências dos usos linguísticos em sala de aula (algo visto como positivo por E4) o que parece é que os discentes esperam um aprofundamento ou uma retomada de conceitos típicos de disciplinas como a Metodologia do trabalho científico e não Leitura, produção e interpretação de textos. Como já apontamos na análise dos conteúdos programáticos, essa confusão sobre os interesses do estudo da língua foi construída institucionalmente, não é de se espantar, portanto, que os estudantes demandem tal instrumentalização.

Acreditamos, pelo contrário, na prevalência da reflexão sobre a instrumentalização. Travaglia (2011, p. 95), por exemplo, dá subsídios para nosso pressuposto ao afirmar que muito dificilmente a maior parte das pessoas, em sua vida diária, precisará, por exemplo, "identificar um objeto direto ou qualquer outro termo da oração [...]”, mas só poderá se constituir como cidadão dentro de uma sociedade científica como a nossa se for capaz de promover a reflexão sobre o mundo circundante. Assim, Travaglia propõe que o ensino de gramática favoreça a reflexão atuando com os seguintes objetivos:

Quadro 2: Objetivos de ensino de teoria gramatical para Luiz C. Travaglia

\begin{tabular}{|c|l|l|}
\hline 1 & Dar informação cultural & Estratégias para atingir o objetivo \\
\hline 2 & $\begin{array}{l}\text { Instrumentalizar com recursos para aplicações } \\
\text { imediatas }\end{array}$ & \\
\hline 3 & $\begin{array}{l}\text { Desenvolver o raciocínio, a capacidade de pensar, } \\
\text { ensinar a fazer ciência }\end{array}$ & $\begin{array}{l}\text { a) Redescobrir teorias existentes } \\
\text { b) Criticar teorias existentes } \\
\text { d) Criar, formular teorias }\end{array}$ \\
\hline
\end{tabular}

Fonte: TRAVAGLIA, 2011, p. 95.

Com o intuito de trazer conhecimento mais significativos para os estudantes de ADS e de MAT, o modelo de Travaglia parece trazer boas soluções. Para PED, também, mas as respostas de PED têm, entre si, um ponto comum um pouco diverso do que apontam os outros cursos: mesmo quando abordam pontos negativos do curso da disciplina, ou que deveriam melhorar, acabam revertendo a situação negativa e transformando-a em positiva. Isso porque, excetuando-se respostas de cunho mais pessoal de E10, E14 e E16, todas as outras demonstram que o que é ruim e deve ser melhorado é a quantidade de tempo disponibilizado para a disciplina de Leitura e produção de textos. Essa constatação, aliada ao fato de que todos os pontos positivos elencados têm alguma relação com os conhecimentos básicos de língua portuguesa, sugere uma problemática a ser levada em consideração com seriedade (FRAGA, 2019), tendo em vista que procedimentos básicos de textualização, componentes elementares de morfologia e sintaxe, conhecimento teórico de flexões de nomes e verbos e das convenções da escrita - elementos que Travaglia (2011), Bagno (2011) e Neves (2018) 
creem essenciais no domínio do manejo da língua -, parecem bastante desconhecidos desse grupo de estudantes que muito brevemente terá a incumbência de alfabetizar crianças e adultos.

Não se trata aqui de culpar os próprios estudantes, mas de ter esse ponto em vista e buscar estratégias como aumento de tempo de atendimento dos professores aos alunos, instituição de plantão de dúvidas, aulas de reforço presencial e/ou on-line etc. com o fito de evitar o efeito bola de neve que esse "desconhecimento" de diversas estruturas teóricas da língua pode causar. Antunes (2003, p. 40) não hesita em dizer que "se nossa prática de professores se afasta do ideal é porque nos falta, entre outras muitas condições, um aprofundamento teórico acerca de como funciona o fenômeno da linguagem". Por isso, para esse grupo de estudantes principalmente, o contato com as teorias linguísticas é mais do que desejável, é um imperativo que deve ser cumprido, sob pena de impossibilitar a reversão do conceito de meritocracia do qual falava Young (1961).

Em tempo, dois comentários merecem ainda um destaque: a) apenas E8 aborda a literatura como uma falta dentro da disciplina, o que é revelador da primazia da suposta objetividade gramatical em detrimento da suposta subjetividade literária, e b) os aspectos apontados por E16 ecoam como quase um pedido de auxílio que, infelizmente, não se resume a apenas este discente, pois, como dissemos, os IFs já nasceram "com uma identidade mais próxima da sociedade brasileira como um todo" (RISTOFF, 2014, p. 744), o que, fatalmente, nos leva a pensar na imensa desigualdade social, econômica, histórica e, por certo, de oportunidades de formação pessoal e cultural que resulta em uma autoestima muito baixa em relação ao uso do português - chegando a afirmar que não sabem português. O drama aqui é, portanto, aquele de que fala Bagno (2011, p. 2223, grifos do autor), quando traz o dado de que "entre os que chegaram ao ensino superior é que prevalecem (68\%) os indivíduos com pleno domínio das habilidades de leitura/escrita e das habilidades matemáticas". Ainda que os dados disponíveis para o autor sejam os de 2009, a prática empírica ainda não é capaz de desmenti-los, passados mais de uma década.

A questão 3 (Qual era a expectativa de vocês sobre a disciplina? Essas expectativas foram alcançadas, superadas ou frustradas? Você consegue ver motivos para isso?), sobre as expectativas que cada aluno depositava sobre si e sobre a disciplina parece ligar-se fortemente com a questão 2 :

Quadro 3: Expectativas discentes

\begin{tabular}{|c|c|c|c|}
\hline ESTUDANTE/ & \multicolumn{3}{|c|}{ QUESTÃO 3} \\
\hline & SUPERADAS & ALCANÇADAS & FRUSTRADAS \\
\hline E1/ TADS & $\begin{array}{l}\text { O curso está me } \\
\text { mostrando exatamente o } \\
\text { que eu esperava e as } \\
\text { expectativas foram } \\
\text { alcançadas. }\end{array}$ & & \\
\hline E2/ TADS & & & $\begin{array}{l}\text { Minhas expectativas era } \\
\text { aprender como escrever } \\
\text { melhor para quando for } \\
\text { mercado de trabalho ou em } \\
\text { trabalhos do if não passar } \\
\text { vergonha. }\end{array}$ \\
\hline E3/ TADS & & $\begin{array}{lr}\text { Obter conhecimento } \\
\text { suficiente } & \text { para } \\
\text { mapear } & \text { minhas } \\
\text { dificuldades } & {[. . .]}\end{array}$ & \\
\hline
\end{tabular}




\begin{tabular}{|c|c|c|c|}
\hline & & Foram atingidas. & \\
\hline E4/ MAT & & & $\begin{array}{l}\text { Eu acreditava que o curso ia } \\
\text { exigir mais [...] essas } \\
\text { expectativas foram frustradas. }\end{array}$ \\
\hline E5/ MAT & $\begin{array}{l}\text { Minhas expectativas } \\
\text { foram superadas. }\end{array}$ & & \\
\hline E6/ MAT & & & $\begin{array}{l}\text { Frustrada, eu como aluna não } \\
\text { consigo montar um artigo } \\
\text { cientifico. O foco das aulas foi } \\
\text { o nivelamento e não o ensino } \\
\text { de textos científicos. }\end{array}$ \\
\hline E7/ MAT & & $\begin{array}{l}\text { Ensino da gramática } \\
e \quad \text { resumos atendeu } \\
\text { minhas expectativas. }\end{array}$ & $\begin{array}{l}\text { O ensino da elaboração do } \\
\text { artigo não foi ruim, mas foi } \\
\text { vago. }\end{array}$ \\
\hline E8/ PED & $\begin{array}{l}\text { Minha expectativa foi } \\
\text { superada com sucesso. }\end{array}$ & & \\
\hline E9/ PED & $\begin{array}{l}\text { Foi totalmente além das } \\
\text { minhas expectativas. }\end{array}$ & & \\
\hline E10/ PED & $\begin{array}{l}\text { Tive um pouco de medo } \\
\text { [...] -mas } \\
\text { surpreendida. }\end{array}$ & & \\
\hline E11/ PED & $\begin{array}{l}\text { O curso vem me } \\
\text { surpreendendo bastante } \\
\text { positivamente. }\end{array}$ & & \\
\hline E12/ PED & & & $\begin{array}{l}\text { Eu entendo a dificuldade de } \\
\text { todos [...], mas algumas } \\
\text { matérias poderiam ser mais } \\
\text { aproveitadas se os prazos } \\
\text { fossem respeitados. }\end{array}$ \\
\hline E13/ PED & & & $\begin{array}{l}\text { Acredito que fiquei um pouco } \\
\text { atrasada devido ao tempo } \\
\text { curto. }\end{array}$ \\
\hline E14/ PED & & & $\begin{array}{l}\text { Esperava ser sido mais lúdico } \\
e \quad \text { dinâmico. Algumas sim } \\
\text { outras não. }\end{array}$ \\
\hline E15/ PED & & & $\begin{array}{l}\text { Esperava ter me saído melhor } \\
\text { na matéria }[. . .] \text {. }\end{array}$ \\
\hline E16/ PED & $\begin{array}{l}\text { A qualidade do curso me } \\
\text { surpreendeu. }\end{array}$ & & \\
\hline
\end{tabular}

Fonte: Elaboração do autor, 2020.

Em relação à TADS, cada um dos estudantes apontou para um dos valores disponíveis, de modo que as respostas para a questão 02 (ver Quadro 1) acabaram sendo confirmadas na descrição das expectativas que foram ou não atendidas, inclusive com E2 apontando para um importante componente social e pessoal: a vergonha por não dominar o léxico com proficiência. As respostas de MAT, por sua vez, revelam forte frustração em relação à dificuldade na escrita de artigos científicos, o que também corrobora as ideias que tinham sido apresentadas nas respostas à questão 2 e sugerem reflexões sobre uma possível equação entre metodologias interativas e tradicionais de ensino. PED, por sua vez, teve suas respostas divididas em expectativas superadas e frustradas, o que também corresponde ao olhar que as respostas anteriores tinham revelado, pois os estudantes de pedagogia haviam revelado boa afinidade com o curso e desejo de poder aprofundar os conhecimentos nessa área de estudos. Natural, então, que as frustrações voltem-se mais para o próprio desempenho do que à disciplina ou docente em si. 
Para além disso, vale comparar as respostas dadas pelos estudantes das licenciaturas (MAT e PED), já que o sentimento entre elas parece bastante oposto em relação à disciplina, mesmo tendo o mesmo docente como regente de ambas as turmas. Quanto a isso, convém lembrar que os sujeitos discentes são seres sociais e desejantes, com características próprias e, por isso mesmo, "A verdade é que o êxito do professor depende não só dele [...], mas também, e muito naturalmente, do contexto em que se insere." (CABRITO, 2009, p. 185). Assim, há que se considerar que, não raro, fatores exteriores à prática docente e/ ou relativos à imagem pessoal do próprio docente interferem de tal modo na recepção do conteúdo ensinado que acaba enviesando o próprio processo de ensino.

Por fim, em relação à questão 4 (Caso você fosse professor/a de língua portuguesa no IF, o que você necessariamente ensinaria? O que não ensinaria de jeito nenhum? Justifique.), a proposta era pedir um exercício de alteridade, fazendo com que os estudantes fizessem uma análise estratégica do que entendiam como fundamento ou não para ser ensinado sobre língua portuguesa.

As repostas dadas revelam dois itens interessantes. Em primeiro lugar, o planejamento do que os estudantes ensinariam tem muito a ver com a concepção do que foi positivo ou negativo no curso e com as expectativas que cada um deles teve, como, por exemplo, ocorre com E1: "mostrar como o estudante pode usar os conhecimentos em favor dele"; E2: "ensinaria um pouco de gramática"; E5: "ensinaria sobre desenvolvimento de textos"; E7: "Focava em exercícios de gramática, interpretação de textos e análises. Colocaria músicas e poemas para os alunos produzirem ideias e reflexões."; E8: "Eu ensinaria gramática, estrategias para escrever e ler, "ensinaria" a refletir [...], ensinaria literatura."; E11: "Focaria no ensino de leitura e escrita."; e E15: "Ensinaria com certeza mto sobre interpretação de textos", em que há forte relação de dependência de sentido no cruzamento das respostas dadas às quatro perguntas.

Em segundo lugar, a decisão de ensinar ou não ensinar um tópico específico exige um foco de concentração que, por diversos motivos, incluindo insegurança, desconhecimento, crença de incapacidade, entre outros, os estudantes não possuem e, por isso mesmo, hesitam e dão respostas vagas ou inconclusivas, fazendo com que apenas E2, E3, E4, E5, E6, E11, E13 e E16 tenham respondido a esse item, mas, mesmo, assim, com respostas que ou diziam que não ensinariam "gramática" (E2, E5 e E6) ou esclareciam que não sabiam o que deixar de ensinar (E4, E11, E13 e E16).

Isso esclarece a necessidade de dar voz aos estudantes, mas não de forma absoluta - visto que eles não dispõem dos critérios técnicos decisórios necessários -, e sim de maneira dialética, a fim de que eles possam colocar questionamentos que sejam capazes de auxiliar na transformação da educação a qual eles merecem receber. Ao mesmo tempo, esclarece a importância do trabalho docente como um trabalho de curadoria, em que os professores são fundamentais para interligar educação, comunicação e cidadania.

\section{Considerações finais}

A intenção deste trabalho não era apresentar um modelo totalmente generalizável de didática da língua portuguesa, mas a oportunidade de acessar os anseios de estudantes de graduação que passaram por disciplinas de língua portuguesa em seus cursos. A partir da delimitação temporal do segundo semestre de 2019, organizamos questões e apresentamos aqui as respostas dos discentes de TADS, MAT e 
PED, analisando-as como unidades separadas e/ ou relacionadas e passíveis de traduzir alguns dos sentimentos dos estudantes dos cursos superiores do IFSP-CJO e, dessa forma, influenciar nas estratégias de ensino-aprendizagem e de estruturação teóricoprática dos próprios cursos.

Para nós, o sentido último de qualquer possibilidade de ensino-aprendizagem é o crescimento moral, social e educacional dos sujeitos envolvidos nesse processo. Dessa maneira, a visão dos docentes como centro do saber ou dos discentes como centro da razão, ambas são descabidas. Faz-se necessário, então, buscar a construção coletiva, dialética e dialógica do conhecimento, alcançando um senso de propósito, isto é, um sentido e um valor para nossos atos, tendo clareza de que o contemporâneo mundo VUCA dentro do qual nos encontramos exigirá de todos e de cada um compreensão do impacto global de nossas escolhas, diante da imprevisibilidade, das constantes mudanças de paradigmas, da complexidade e da ambiguidade de nossos tempos. Assim é que "os objetos do ensino devem ser coisas que as pessoas ainda não sabem" (BAGNO, 2011, p. 28) e, por isso mesmo, é que devem estar ligados à reflexão sobre a língua, não à reprodução de nomenclaturas gramaticais.

Preparar sujeitos capazes não só de se adaptar a este mundo, passivamente, mas também de modificá-lo, adaptá-lo e transformá-lo ativamente com a intenção de atingir o próprio bem estar. Confiar na adaptabilidade dos estudantes, mas também prepará-los para tomar decisões que não sejam apenas reações ao meio. Ensinar a seguir regras, mas não negligenciar os sentimentos e as intuições na tomada de decisão. Tudo isso é possível por meio de uma atuação segura dos docentes e tudo isso pode ocorrer por meio de aulas de língua portuguesa, porém isso não quer dizer que seja fácil ou mesmo que seja o que as instituições de ensino desejam. Escutar os estudantes, como queria Freire (1981, 2008), e balizar essa escuta com os professores é o primeiro passo para que a educação seja verdadeiramente inclusiva e democrática.

Assim, queremos concluir apontando para o difícil papel dos docentes de língua portuguesa na educação profissional dentro dos Institutos Federais que, mesmo não tendo formação suficiente para associar o conhecimento específico de sua área de atuação às licenciaturas e aos cursos tecnológicos, não desanimam diante das dificuldades e esforçam-se por ingressar no mundo de estudantes de cursos tão próximos e ao mesmo tempo tão distantes de sua própria formação, como Pedagogia, Matemática e Tecnologia em Análise e Desenvolvimento de Sistemas.

\section{Referências}

ALLEN, A. Michael Young's The Rise of the Meritocracy: A Philosophical Critique. British Journal of Educational Studies. v.59, n.4, p. 367-382, 2011.

ANTUNES, I. Aula de português: encontro e interação. São Paulo: Parábola Editorial, 2003.

AXT, M. Comunidades Virtuais de Aprendizagem e Interação Dialógica: do corpo, do rosto e do olhar. Filosofia Unisinos. v.7, p. 256-268, 2006.

BAGNO, M. Gramática pedagógica do português brasileiro. São Paulo: Parábola Editorial, 2011.

BAKHTIN, M. M. Estética da Criação Verbal. Tradução Paulo Bezerra. 2. ed. São Paulo: Martins Fontes, 2003. 
BARDIN, L. Análise de conteúdo. São Paulo: Edições 70, 2011.

BERNSTEIN, L. E. The perceived importance of vuca-driven skills for $21^{\text {st }}$ century leader success and the extent of integration of those skills into leadership development programs. Des Moines, Iowa, 2014. (Tese de doutoramento). Drake University.

BOURDIEU, P. Escritos de Educação. Org. Maria Alice Catani; Afrânio Catani. Petrópolis: Vozes, 1998.

BRASIL. MEC. Lei 11.892, de 29 de dezembro de 2008 (Institui a Rede Federal de Educação Profissional, Científica e Tecnológica, cria os Institutos Federais de Educação, Ciência e Tecnologia, e dá outras providências).

Lei $n^{\circ} 12.711$, de 29 de agosto de 2012 (Lei de Cotas: dispõe sobre o ingresso nas universidades federais e nas instituições federais de ensino técnico de nível médio).

CABRITO, B. G. Avaliar a qualidade em educação: avaliar o quê? Avaliar como? Avaliar para quê? Caderno Cedes. Campinas, v.29, n.78, p. 178-200, maio/ago., 2009.

CAMPOMAR, M. C. Do uso de "estudo de caso" em pesquisas para dissertações e teses em administração. Revista de Administração da USP. São Paulo, v.26, n.3, p. 95-97, jul./set., 1991.

CASTRO, C. M. A prática da pesquisa. São Paulo: McGraw-Hill do Brasil, 1977.

CHARAUDEAU, P. Dize-me qual é teu corpus, eu te direi qual é a tua problemática. Revista Diadorim. Rio de Janeiro, v.10, p. 1-23, dez., 2011.

ECONOMIST. Os segredos da meritocracia. Tradução de Terezinha Martinho. Estadão. 24 fev, 2018.

FAIRCLOUGH, N. Discurso e Mudança Social. Brasília: Edu - UnB, 2008.

FARACO, C. A. Linguagem e diálogo: as ideias linguísticas do círculo de Bakhtin. São Paulo: Parábola Editorial, 2009.

FRAGA, É. Candidatos a professor têm notas abaixo da média do país. Folha de $S$. Paulo. Educação. 5 dez, 2019.

FREIRE, P. Pedagogia do oprimido. 9. ed. Rio de Janeiro: Paz e Terra, 1981. 2008. Professora sim, tia não: cartas a quem ousa ensinar. São Paulo: Olho d'Água,

GERRING, J. What Is a Case Study and What Is It Good for? American Political Science Review. Los Angeles, v.98, n.2, p. 341-354, May, 2004.

GODOY, A. S. Introdução a pesquisa qualitativa e suas possibilidades. Revista de Administração de Empresas. São Paulo, v.35, n.2, p. 57-63, Mar./Abr., 1995. 
HERACLEOS, L. Discourse, Interpretation, Organization. Cambridge: Cambridge University Press, 2006.

HORNEY, N.; PASMORE, B.; O'SHEA, T. Leadership Agility: A Business imperative for a VUCA world. People \& Strategy. v.33, n.4, p. 32-38, 2010.

KOCH, I. G. V. Argumentação e linguagem. São Paulo: Cortez, 2004.

LIMA, L. C. A avaliação institucional como instrumento de racionalização e o retorno à escola como organização formal. Educação e Pesquisa. São Paulo, v.41, n. especial, p. 1339-1352, dez., 2015.

MACHADO, L. R. S. Diferenciais inovadores na formação de professores para a educação profissional. Revista Brasileira da Educação Profissional e Tecnológica. Brasília, v.1, n.1, p. 8-22, jun., 2008.

MARCONI, M. A.; LAKATOS, E. M. Fundamentos de metodologia científica. 5. ed. São Paulo: Editora Atlas, 2003.

MEIER, M.; GARCIA, S. Mediação da aprendizagem: contribuições de Feuerstein e de Vygotski. 7. ed. Curitiba: Edição do autor, 2007.

MOURA, D. H. A formação docente para a educação profissional tecnológica. Revista Brasileira da Educação Profissional e Tecnológica. Brasília, v.1, n.1, p. 23-28, jun., 2008.

NEVES, M. H. de M. A gramática do português revelada em textos. São Paulo: Editora Unesp, 2018.

ORLANDI, E. P. Análise do discurso: princípios e procedimentos. Campinas: Pontes, 2009.

PIZA, S. L. T. Empresa, educação e meritocracia: a propósito de Michael Young. Revista da Faculdade de Educação. São Paulo, v.11, n.1/2, p. 211-222, jan./dez., 1985.

POSSENTI, S. Por que (não) ensinar gramática na escola. Campinas: ALB, Mercado das letras. 2006.

RICHARDSON, R. J. Pesquisa Social: Métodos e Técnicas. São Paulo: Atlas, 1999.

RISTOFF, D. O Novo Perfil do Campus Brasileiro: uma análise do perfil socioeconômico do estudante de graduação. Revista da Avaliação da Educação Superior (Campinas), São Paulo, Sorocaba, v.19, n.3, p. 723-747, nov., 2014.

ROCHA, C. O livro que criou o termo 'meritocracia' é uma distopia. Nexo jornal. n.6, nov, 2017.

SILVA, A. J. H. da. Metodologia de Pesquisa: Conceitos Gerais. Paraná: Unicentro, 2014. 
SKINNER, D.; TAGG, C.; HOLLOWAY, J. Managers and research: the pros and cons of qualitative approaches. Management Learning. v.31, n.2, p. 163-179, 2000.

TRAVAGLIA, L. C. Gramática ensino plural. 5. ed. São Paulo: Cortez, 2011.

TRIVIÑOS, A. N. S. Introdução à pesquisa em Ciências Sociais: a pesquisa qualitativa em Educação - o positivismo, a fenomenologia, o marxismo. 5. ed. São Paulo: Atlas, 2009.

YOUNG, M. The rise of the meritocracy, 1870-2033: an essay on education and equality. Bristol, Great Britain: Penguin Books, 1961.

Recebido em 30 de maio de 2020

Aceito em 06 de julho de 2020 